\title{
Contributory Infringement Rule and Patents
}

\author{
Corinne Langinier* and Philippe Marcoul ${ }^{\dagger}$
}

August 2007

\begin{abstract}
The contributory infringement rule assesses liability to a third party that contributes to the infringement of a patent. Not only are firms that directly infringe liable, those that indirectly contribute are also liable. We investigate how this rule affects the creation of a network of members (e.g., an e-commerce network). We find that the enforcement of indirect liability does not induce more trials in equilibrium. Firms settle out-of-court, but because of the threat of trial, the network size decreases and the social welfare is reduced. Surprisingly, we find that if the compensation paid by the indirect infringers is high, the rule does not benefit the patentholder and may not even give enough R\&D incentives ex ante. It is possible to find a direct compensation for the patentholder that is socially preferable.
\end{abstract}

Keywords: Patents; Network; Infringement

JEL classification: K11 (Property Law), K41 (Litigation Process), O34 (Intellectual Property Rights), D62 (Welfare Economics, Externalities)

\footnotetext{
*Iowa State University, Ames. langinier@econ.iastate.edu

${ }^{\dagger}$ Iowa State University, Ames. marcoul@iastate.edu
}

We would like to thank Jennifer Reinganum, participants in the Economics of Innovation and Science Policy workshop at ISU, and participants in the IIOC05 in Atlanta and the WEAI06 in San Diego for helpful comments. 


\section{Introduction}

Firms can be accused of direct infringement if they illegally use an innovation protected by a patent (copyright or trademark). But they can also be accused of indirect infringement as soon as they help to sell or promote products or services of a company that infringes upon a patent. ${ }^{1}$ Formally, patent law also makes liable someone who actively induces infringement of a patent or who contributes to the infringement by another if he "offers to sell or sells a component of a patented machine, manufacture, combination or composition, or a material or apparatus for use in practicing a patented process," as required by 35 U.S.C. section 271 (c).

In this paper, we wonder to what extend Intellectual Property (IP) laws should allow IP owners to sue people who are not directly involved in the infringement, but contribute to it. Therefore, we investigate whether the contributory infringement rule (hereafter, the CI rule) induces more trials, whether patent owners benefit from its enforcement, and whether this rule is socially desirable.

In the e-commerce world, this rule takes on an important dimension because of the network structure of the Internet and the increasing number of e-commerce patents. Indeed, businessmethod software is one of the fastest-growing categories of new patents, and software patents account for fifteen percent of all patents (Bessen and Hunt, 2004). Nowadays, patents owned by Amazon.com, Priceline.com and eBay.com, among others, exist for methods of accepting credit cards over the Internet, for processing orders and transactions of all types, and for alerting consumers of the status of their orders. The network structure of the Internet has an indirect effect on the value of these patents, due to the CI rule.

To fully capture the potential effects of this rule, let us have a better understanding of the structure of the relationships on the Internet. The existence of the network induces specific relationships between firms: their web sites are cross-linked and they advertise other web sites. A given web site of firm $B$ may use, via hyperlinks or cross promotions, some of the software (or some of the resources) of another web site created by firm $C$. Both firms can possibly contract

\footnotetext{
${ }^{1}$ For instance, on March 23, 1999, the on-line auction eBay was sued by Network Engineering Software (NES) for "using third party software packages that infringe the NES' patent," Bloomberg news; "NES sues eBay, alleges Patent Infringement," CNET, news.com.
} 
upon the provision of such software. Consequently, the Internet can be seen as a network of contracts in which firms are committed to other firms and, thus, become liable when the nature of the shared item is altered. Imagine that another firm, say firm $A$, holds a patent on software that firm $B$ uses; that firm $B$ has contracted with firm $C$; and, furthermore, that firm $C$ derives benefits from this software. Is firm $C$ liable if firm $B$ has infringed upon firm $A$ 's patent? In order to realize the magnitude of such an issue, consider the following example (Rivette and Kline, 2000). In 2000, Amazon.com had about 250,000 members in its associated program. Each of these members received a payment of between 7 and 15 percent of the profit from any book or video sold to consumers that they referred. Imagine now that another firm that held a specific patent filed a lawsuit against Amazon.com for infringement. The CI rule allows the patentholder to sue the 250,000 members in the case of a successful trial, because they contributed to the infringement. They would appear as third parties in the infringement, but would have their share of responsibility. Indeed, from a legal viewpoint, in the U.S. an indirect infringer should have or should have had some element of knowledge that he is contributing to the infringement (Lemley, 2005). For instance, in the context of copyrights, we learn from the Napster case that an Online Service Provider should check whether the materials it diffuses are copyrighted, and cannot simply pretend it did not know about the infringement (Boldrin and Levine, 2003). Note that many other countries (e.g., Japan and Korea) do not even require any knowledge of the direct infringement in order to hold the contributory infringer liable (Jong, 2000).

Although the previous story is hypothetical, there exists anecdotal evidence that firms plan to make third parties liable in the case of a successful direct infringement trial. British Telecommunications (BT) lost a recent patent infringement lawsuit against Prodigy. ${ }^{2}$ The Sargent (hyperlink) patent describes a system in which multiple users, located at remote terminals, can access data stored in a central computer. BT has argued that the Internet infringes the Sargent patent and that Prodigy facilitates infringement by its subscribers by providing them with access to the Internet. BT wanted to have all of the Internet service providers pay a license fee for hosting pages that use hyperlinks (the building blocks on the web). In the case of a

\footnotetext{
2 "Hyperlink patent case fails to click," Matt Loney, CNET, News.com, August 23, 2002. See also Rivette and Kline (2000) published at the beginning of the lawsuit.
} 
successful trial, BT would have sued all Internet service providers. This example gives an idea of the magnitude of such a rule and its potential consequences.

However, we should also note that, so far, we have not witnessed cascading trials with regard to the Internet due to the CI rule. We attempt to offer a possible explanation by investigating the effects of the CI rule on the creation and size of a network of members. The members are willing to be part of this network only if they can cover the costs of legal lawsuits linked to the possibility of indirect infringement. However, in many situations, disputes over intellectual property rights (IPRs) are not settled in court. In our framework, we allow for the possibility of an out-of-court settlement in which a license fee can be negotiated between the direct infringer and the patentholder; therefore, trial needs not always be the outcome of the game.

Our main focus is to determine whether and how this rule affects the creation of a network, and whether it is socially harmful. To achieve this goal, we propose a three-stage game. At the outset, a business-method innovation (or new software) has been made and patented. A potential infringer discovers an idea that may exploit the potential value created by the innovation and decides whether to enter the market or not. As such, it might infringe upon the patented innovation. If it does, the detection of the infringement is only possible after the membership program has been created and all firms start enjoying returns. In the first stage, the potential infringer creates a network of members. He makes a "take-it-or-leave-it" offer to potential members, and they all accept or refuse it. Indirect infringers have knowledge of the risk of infringement, and therefore are liable whenever it is established that there is direct infringement. In the second stage, if the infringement occurs, it is immediately detected by the patentholder, who decides whether to go to court or to settle out-of-court. When a settlement is reached, the infringer pays the patentholder a license fee that is determined as a Nash Bargaining solution. In the third period, if a trial occurs, with some probability, the patentholder wins the case and then can sue all of the members for contributory infringement if the rule is enforced. Because indirect infringers are aware of their possibly faulty behavior and of the risk of a trial associated with it, proving indirect infringement only requires an underlying act of infringement. Therefore once the direct infringer has been successfully sued, the patentholder can sue all of the indirect infringers. We assume that success at the first trial insures success against the members. 
We show that network size is affected by the CI rule. One of our findings is that the enforcement of this rule does not induce more trials in equilibrium, even though it decreases network size. If the outcome of the litigation process is a trial, the members of the network anticipate that they risk being sued and, therefore, need adequate compensation to be part of the membership program. As a result, fewer members join. In the case of a settlement, the threat of trial has the same effect: it reduces the size of the network. This is, however, harmful to consumers and firms, as it induces a smaller network, and thus reduces social welfare. Furthermore, the patentholder does not even benefit from the high damages paid by indirect infringers. Indeed, the effect of network size reduction outweighs the direct effect of the gain from more damages and, therefore, the patentholder is worse off. Moreover, we find that even if the patentholder can be equally compensated under both regimes (with and without contributory infringement), ex ante the regime without is better for society in general. However, because the revenue of the patentholder comes mainly from licensing or damages, we show that if society's goal is to maximize ex ante R\&D incentives of the patentholder, there exists a low level of contributory damage per member that maximizes the expected license fee (or expected amount of damages). This means that if the CI rule is enforced, third parties must not be too liable in case of infringement. Indeed, if the level of indirect infringement increases, it immediately makes the patentholder worse off. On the other hand, society is always worse off, no matter what the indirect infringement level is.

The paper is organized as follows. Section 2 discusses related literature. In section 3 we introduce the model, and we define the penalty rule adopted in case of trial and the license fee paid by the infringer in case of settlement. Section 4 is devoted to the litigation process and to the analysis of the conditions under which the patentholder prefers to settle out-of-court. In section 5 we focus on network creation and on the different contracts offered by the infringer to the members. Section 6 contains the details of the subgame perfect Nash equilibrium that specifies which contract is offered and the outcome of the game. In section 7 we investigate the implications of the CI rule on total welfare. We discuss some extensions in section 8. Section 9 concludes. 


\section{Related Literature}

There is an ongoing debate about the existence of software patents and, in particular, it has been argued that this kind of innovation is not very costly to produce and that licensing is just a rent-seeking activity. Several studies have pointed out the necessity of tailoring the patent system to this specific kind of innovation (Mergers, 1999; Shapiro, 2001). Here, we do not address the problem of whether these patents should be granted; we simply consider that they exist, as they actually do, and that they can eventually be invalidated in court.

More broadly, the economic literature on IPRs is concerned with the litigation issues of infringement and the study of how patentholders make their decisions to settle out-of-court or to sue for damages. ${ }^{3}$ In a cooperative approach to litigation and settlement, a trial can be Pareto optimal and the threat of litigation can be effective in preventing entry (Aoki and Hu, 1999). Relatedly, Crampes and Langinier (2002) adopt a cooperative approach to study a setting in which monitoring is used as a tool to prevent entry by infringers. In our setting, we also use a cooperative approach to study the litigation process.

The value of patentholder protection depends on the adopted doctrine of damages. Indeed, in the case of trial, there exist two U.S. damage doctrines: "lost profit" and "unjust enrichment." Under some circumstances one doctrine is superior to the other for generating R\&D incentives (Schankerman and Scotchmer, 2001). When the innovator holds a patent on a research tool and is unable to develop it, he is better off when the doctrine of damages is "unjust enrichment" (see also Kaplow and Shavell, 1996; Blair and Cotter, 1999). In our setup, we do not consider the possibility of injunctions, but we assume that the patentholder is aware of the infringement and then decides to threaten the infringer and eventually to bargain over a license.

Settlement negotiations are obviously not limited to IPRs. There is a broad literature on settlement and litigation (see Daughety, 2000, for a survey for "non-terribly technical non specialists," and also Daughety and Reinganum, 2005). Recently, emphasis has been put on the problem of information that can be transmitted to subsequent litigants after a first trial occurs.

\footnotetext{
${ }^{3}$ A patentholder may decide to award a license to an infringer to avoid litigation on the issue of patent validity (Meurer, 1989). According to Shapiro (2003), settlements are not always anti-competitive if they leave consumers as well off as they would have been from litigation.
} 
Here, we adopt a simple viewpoint: once the infringer is found guilty of infringement, so are the third parties.

Our paper is also related to the law and economics literature pertaining to litigation and manufacturer liability in the case of harm to consumers (Spier, 2005; Hay and Spier, 2005). Hay and Spier (2005) show that if consumers (parties directly liable in case of damages) have deep pockets, they should be the only ones to be liable. In this case, consumers take the optimal degree of care and they demand optimal safety features. However, in the case of non-solvency, the manufacturer (indirect liable party) should only pay what the direct liable party cannot pay. Even though our setting is different, we find similar results. Indeed, we find that society would be better off if only the direct infringer were to be liable. However, we do not address the issue of solvency because we assume that the benefit to the indirect infringers is a fraction of the direct infringer's profit.

Along the same lines, Landes and Litchman (2003) wonder how far copyright liability should extend beyond any direct infringement. When third parties can discourage infringement (by making infringement more difficult, for instance), indirect liability can serve as a means to reduce illegal behavior. However, this is not always possible. If there are legitimate uses, the benefits associated with them must be weighed against the harm caused by illegitimate uses. Society may be better off without indirect liability when it is too costly to distinguish legal from illegal uses.

Furthermore, reducing copyright infringement might be done at the price of deterring innovation. In the digital copyright world, Lemley and Reese (2004) wonder how to reduce illegal infringement behavior without reducing innovation.

To the best of our knowledge, our paper is the first in the economic literature to analyze the CI rule and its consequences. We discuss the importance of this rule within the framework of a commercial network formation within the Internet.

\section{The Model}

We consider a three-period model with $m+2$ players: a patentholder (named firm $H$ ), a potential infringer (firm $I$ ) and $m$ members of a network. The network of members is created by firm 
$I$, as is the case with the Amazon.com example presented in the introduction and, thus, $m$ is optimally determined by firm $I$. At the outset, firm $H$ has a patent on an innovation that can be used by firm $I,{ }^{4}$ which decides whether to enter the market or not knowing that he is at risk of infringing. Therefore, there is probability $q$ that firm $I$ will infringe upon firm $H$ 's patent. The entry decision could be made after (or at the same time as) the creation of the network without altering our results. For expositional purposes, we assume that the innovation, the patenting, and the entry decisions are made at the outset of the game. However, to complete our analysis, in the last section we study the entry decision.

\section{Timing}

1. (Network creation and contracts) In the first period, a network (or membership program) of size $m$ is created by firm $I$. He makes a "take-it-or-leave-it" offer to the potential members of the network that consists of the share of profit $\alpha$ that each member $i$ will get for $i=1, \ldots, m$. The members decide whether to accept or to refuse the offer.

2. (Litigation process) In the second period, if the infringement occurs, firm $H$ detects it immediately, and observes the size of the network, as well as the share of profit offered to the members. He then decides to litigate, which may result in settlement or trial. ${ }^{5}$ If a settlement is reached, firms $H$ and $I$ choose the level of license fee (Nash Bargaining solution) that has to be paid by firm $I$, and the commercial network is exploited for two periods, the second and the third.

3. (Trial and contributory infringement) In the third period, if firms $H$ and $I$ go to court, with probability $p_{H}$ firm $H$ wins the trial and the damages are paid according to the outcome of the trial. If the result of the lawsuit is in favor of firm $H$, then he is entitled

\footnotetext{
${ }^{4}$ A patent granted to Amazon.com in 1999, number 5,960,411 entitled "method and system for placing a purchase order via a communication network patent," is an example of such a method that was already used in-house by many firms.

${ }^{5}$ Crampes and Langinier (2002) consider a model of infringement in which the patentholder must first incur a cost to identify the infringer, before deciding whether to go to court, to settle on an agreement, or to renunciate any pursuit. Here, for the sake of simplicity, we assume that detection is costless, assuming a cost of detecting infringement would not change the results.
} 
to sue the $m$ members for contributory infringement if this rule is enforced.

\section{Expected payoffs}

Each firm earns a payoff during the two periods after the creation of the network (i.e., periods two and three). To simplify, we assume that there is no discounting.

Let $\Pi_{I}(m)$ denote the payoff of the infringer, where $\Pi_{I}^{\prime}(m)>0, \Pi_{I}^{\prime \prime}(m)<0$. Each member $i$ gets a fraction $\alpha \in[0,1 / m]$ of it, namely, $\alpha \Pi_{I}(m)$, and therefore, the gross payoff of the infringer is $(1-\alpha m) \Pi_{I}(m)$, which is an inverted U-shaped function where $1-\alpha m \geq 0$. On one hand, the members bring consumers and, therefore, increase the profit of the infringer. But on the other hand, for being part of the membership program and bringing consumers to the infringer, the members get a fraction of the profit of the infringer, which reduces his profit. Hence, there is a trade-off between the benefit from having one more member and the cost associated with this member.

If there is infringement and a settlement is reached, the patentholder gets an expected payoff of

$$
G_{H}=2 \widetilde{\Pi}_{H}-c_{H}^{s}+L^{N B S}
$$

where $\widetilde{\Pi}_{H}$ is the payoff earned by the patentholder in every period when entry has occurred, $c_{H}^{s}$ is the cost associated with a settlement (transaction cost of patent licensing) that we normalize to be zero, and $L^{N B S}$ the total negotiated license fee issued from a Nash Bargaining Solution (that we derive later). The expected payoff of the infringer is

$$
G_{I}=2(1-\alpha m) \Pi_{I}(m)-c_{I}^{s}-L^{N B S},
$$

where $c_{I}^{s}$ is the cost associated with a settlement paid by firm $I$. Each member $i$ gets

$$
G_{i}=2\left(\alpha \Pi_{I}(m)-\gamma\right)
$$

where $\gamma$ represents the cost of maintaining the connection to the network. We assume, without loss of generality, that this cost is borne by the members.

If a trial is the result of the litigation process, the expected payoff of the patentholder is

$$
d_{H}=\widetilde{\Pi}_{H}-c_{H}^{t}+p_{H}\left(\Pi_{H}+R_{H}\right)+\left(1-p_{H}\right) \widetilde{\Pi}_{H},
$$


where $\Pi_{H}$ is the payoff of firm $H$ when firm $I$ can no longer exploit his network with $\Pi_{H} \geq \widetilde{\Pi}_{H}$, $c_{H}^{t}$ is the cost incurred by firm $H$ in case of a trial, $p_{H}$ the probability that he wins the trial, and $R_{H}$ the penalty that the patentholder receives if he wins the case. ${ }^{6}$ This penalty depends crucially on the existence of the CI rule. If it is enforced, firm $H$ will first receive a compensation from the infringer for direct infringement before launching a lawsuit against the members of the network. We assume that once the infringer loses the lawsuit, all of the members are liable, and firm $H$ is entitled to receive compensation from all of them. ${ }^{7}$ Further, we initially assume that it is costless for the patentholder to sue the members. In section 7 , we relax this assumption and show that our results still hold. Hence,

$$
R_{H}=R_{H, I}+\sum_{i=1}^{m} R_{H, i}
$$

where $R_{H, I}$ is the penalty paid by firm $I$ to firm $H$ and $R_{H, i}$ the penalty paid by each member $i$ to firm $H$. The expected payoff of firm $I$ is

$$
d_{I}=(1-\alpha m) \Pi_{I}(m)-c_{I}^{t}+\left(1-p_{H}\right)(1-\alpha m) \Pi_{I}(m)+p_{H}\left(\Pi_{I}^{t, l}-R_{H, I}\right),
$$

and each member $i$ gets

$$
d_{i}=\alpha \Pi_{I}(m)-\gamma+\left(1-p_{H}\right)\left(\alpha \Pi_{I}(m)-\gamma\right)+p_{H}\left(\alpha \Pi_{I}^{t, l}-c_{i}^{t}-R_{H, i}\right), \text { for } i=1,2, \ldots, m
$$

Without loss of generality, we posit that $\Pi_{I}^{t, l}=0$, and we normalize $c_{i}^{t}=0$. Indeed, if the infringer loses the case, he will be prevented from using the protected innovation and, thus, will be forced to use a less profitable one that may drive the payoff down to zero. Once the infringer gets zero profit, each member will get zero profit, as well. Therefore, we can rewrite the expected

\footnotetext{
${ }^{6}$ We make the assumption that each party pays its own legal costs. In the United States, each party bears its own legal costs of trial unless it can be proven that there was a willful infringement (See Meurer, 1989; Aoki and $\mathrm{Hu}, 1999)$.

${ }^{7}$ This is a simplifying assumption and a shortcut. In practice, although infringement liability is a necessary condition for contributory infringement, the members will have to be sued for contributory infringement by the patentholder and each member's liability will still have to be established by the court. Our result would not change qualitatively if we assumed that the chances of winning the trial for contributory infringement were strictly less than one. We discuss a sequential bargaining process in section 8 in which negotiation is possible between the patentholder and the members.
} 
payoff of firm $I$ as

$$
d_{I}=\left(2-p_{H}\right)(1-\alpha m) \Pi_{I}(m)-c_{I}^{t}-p_{H} R_{H, I},
$$

and of each member as

$$
d_{i}=\left(2-p_{H}\right)\left(\alpha \Pi_{I}(m)-\gamma\right)-p_{H} R_{H, i} .
$$

If there is no infringement, the expected payoffs of firm $H$, firm $I$ and each member $i$ are, respectively,

$$
\begin{gathered}
g_{H}=2 \widetilde{\Pi}_{H}, \\
g_{I}=2(1-\alpha m) \Pi_{I}(m), \\
g_{i}=G_{i}=2\left(\alpha \Pi_{I}(m)-\gamma\right) .
\end{gathered}
$$

\section{The penalty rule}

We now define the penalty rule more precisely. The law enunciates two doctrines of damages, "unjust enrichment" and "lost profit and reasonable royalty." Each doctrine has very distinctive purposes and is directed toward a specific target. The former doctrine states that the infringer is required to pay the profits from infringement back to the patentholder. The latter doctrine compensates the patentholder for the foregone profit due to the infringement. This doctrine of damages is somewhat designed to maintain the patentholder's incentives to invest in R\&D activities. We do not make any specific assumptions with respect to the doctrine of damages used by the court. Rather, we assume that the penalty paid to the patentholder will represent a fraction of the gross payoff of the infringer and, if applicable, of the indirect infringers. Consequently,

$$
R_{H, I}=\beta_{I}(1-\alpha m) \Pi_{I}(m) \text { and } R_{H, i}=\beta \alpha \Pi_{I}(m)
$$

where $\beta_{I}, \beta \in[0,1]$.

This assumption, consistent with Schankerman and Scotchmer (2001), may encompass the two doctrines of damages. For instance, $\beta_{I}=\beta=1$ corresponds to the "unjust enrichment" doctrine. Note that substantial supra compensatory sanctions are possible if $\beta_{I}>1$. Such damages are possible when the plaintiff (i.e., the patentholder) can prove that there was willful infringement (if $q=1$ ) and, in this case, the penalty paid may incorporate punitive damages. ${ }^{8}$

\footnotetext{
${ }^{8}$ The doctrine of "unjust enrichment" was used in the famous case of Kodak versus Polaroid. See Warshofsky (1994) for a detailed explanation of this case.
} 
A high $\beta$ stands for a high level of liability of the secondary infringers, whereas $\beta=0$ stands for a situation in which the CI rule is not enforced. Hence, $\beta$ measures the level of contributory infringement liability.

\section{Nash Bargaining solution}

To complete the description of the payoffs, we need to specify the negotiated license fee. In the second stage of the game, if a settlement is reached, the patentholder and the infringer determine the level of the royalty fee that firm $I$ will pay to firm $H$. We compute this level as the solution of a Nash Bargaining game ${ }^{9}$ and, therefore, the fee $L$ is the solution of the following program

$$
\max _{L}\left[2 \widetilde{\Pi}_{H}+L-d_{H}^{\rho}\right] \times\left[2(1-\alpha m) \Pi_{I}(m)-c_{I}^{s}-L-d_{I}\right]^{1-\rho},
$$

where $\rho$ (respectively, $1-\rho$ ) represents the bargaining power of firm $H$ (respectively, firm $I$ ). The first bracket represents the difference between the profit from settlement and the profit from trial for firm $H$, and the second bracket represents the difference between the settlement payoff and the trial payoff for firm $I$. The Nash Bargaining two-period license is

$$
\begin{aligned}
L^{N B S}(m, \beta)= & p_{H}(1-\alpha m) \Pi_{I}(m)\left(\rho+\beta_{I}\right)+p_{H}(1-\rho) \beta \alpha \Pi_{I}(m) m \\
& +(1-\rho) p_{H}\left(\Pi_{H}-\widetilde{\Pi}_{H}\right)+\rho\left(c_{I}^{t}+c_{H}^{t}-c_{I}^{s}\right)-c_{H}^{t} .
\end{aligned}
$$

For any $m$, it is straighforward that when the CI rule is enforced $(\beta>0)$ the optimal license fee is higher than in the absence of such rule, i.e., $L^{N B S}(m, \beta)>L^{N B S}(m, 0)$. Even though firms settle out-of-court, the threat point is the trial outcome and, therefore, if the rule is enforced, the license fee includes a fraction of the profit of the members that the patentholder can claim in case of infringement. Whether or not the outcome is a trial, the threat of the trial affects the members' payoffs. Therefore, the license fee increases with the penalty paid by the infringer(s), $R_{H}$. It also increases with the probability of winning for the patentholder.

To solve the game, we define the subgame perfect Nash equilibrium. To do so, we go backward and start with the very last decision: the litigation decision of firm $H$. Then we specify the different contracts that firm $I$ can offer to the members if he decides to infringe upon the innovation. Among those contracts, firm $I$ chooses the optimal contract. We then derive the subgame perfect Nash equilibrium.

\footnotetext{
${ }^{9}$ This is in the same vein as Aoki and $\mathrm{Hu}$ (1999) or Crampes and Langinier (2002).
} 


\section{Litigation Process}

The patentholder prefers to settle out-of-court whenever $G_{H} \geq d_{H}$ holds true. This inequality is, in fact, equivalent to having

$$
2 \widetilde{\Pi}_{H}+2(1-\alpha m) \Pi_{I}(m)-c_{I}^{s} \geq d_{H}+d_{I},
$$

which indicates that a settlement occurs whenever the sum of the payoffs in case of settlement is higher than the sum of the threat point payoffs (i.e., the payoffs in case of trial). We can rewrite this inequality as

$$
\Delta-\left(\Pi_{H}-\widetilde{\Pi}_{H}\right)+(1-\alpha m) \Pi_{I}(m)-\beta \alpha m \Pi_{I}(m) \geq 0,
$$

where $\Delta=\left(c_{I}^{t}+c_{H}^{t}-c_{I}^{s}\right) / p_{H}$, in which the term in parenthesis represents the aggregate cost savings from settling out-of-court. We assume that $\Delta>0$, as it seems natural that the total cost associated with a trial is higher than the total cost associated with a settlement, no matter who bears those costs. We further assume that $\Delta-\left(\Pi_{H}-\widetilde{\Pi}_{H}\right) \geq 0$. This assumption, which is stronger than needed, insures that the indirect liability level $\beta$ always plays a role in the decision of the patentholder to go to court or to settle out-of-court. In the absence of the CI rule $(\beta=0)$, a settlement will always be reached, as $\Delta-\left(\Pi_{H}-\widetilde{\Pi}_{H}\right)+(1-\alpha m) \Pi_{I}(m)>0$. However, in the presence of the CI rule $(\beta>0)$, firm $H$ prefers a settlement only if (12) holds true.

For any given share of profit $\alpha>0$, and for any given size of network $m>0$, there exists a value $\widetilde{\beta}>0$, such that $\Delta-\left(\Pi_{H}-\widetilde{\Pi}_{H}\right)+\Pi_{I}(m)-(1+\beta) \alpha m \Pi_{I}(m)=0$, where $\widetilde{\beta}=\left(\Delta-\left(\Pi_{H}-\right.\right.$ $\left.\left.\widetilde{\Pi}_{H}\right)+(1-\alpha m) \Pi_{I}(m)\right) / \alpha m \Pi_{I}(m)$. Therefore, for any $\beta \in(0, \widetilde{\beta})$, firm $H$ prefers a settlement over a trial, whereas for any $\beta>\widetilde{\beta}$, firm $H$ prefers to go to court. We summarize this finding in the following lemma:

Lemma 1 For given $\alpha>0$ and $m>0$,

- for relatively small levels of contributory infringement $(\beta \leq \widetilde{\beta})$ the patentholder prefers a settlement, and

- for higher levels of contributory infringement $(\beta>\widetilde{\beta})$ the patentholder prefers a trial. 
Overall, firm $H$ prefers a trial for greater values of $\beta$ because the benefit from suing indirectly liable members outweighs the cost of the trial (as long as $p_{H}$ is not too small). In any case, even if a settlement occurs in the absence of the CI rule, it does not necessary mean that a settlement will occur when indirect infringers are liable. In other words, with contributory infringement, trials should be more likely to occur than without the CI rule.

\section{Network Creation and Contracts}

We now turn to the first period decisions of firm $I$ : the optimal size of the network $m$ and the share of the profit $\alpha$ for each member $i$ if infringement occurs. ${ }^{10}$ We analyze these actions given the strategy that the members accept or refuse the offer, and that firm $H$ chooses his settlement decision based on the first period's actions. Firm $I$ correctly anticipates what the outcome will be, as we assume perfect information. Thus, firm $I$ makes an offer that is conditional upon whether the outcome is a trial or a settlement: $\alpha_{t}$ or $\alpha_{s}$. Furthermore, the size of the network also depends on whether the outcome is a trial or a settlement: $m_{t}$ or $m_{s}$. We denote $(m, \alpha)$ a contract that offers a share of profit $\alpha$ to each member $i$ where $i=1, \ldots m$, where $\left(m_{s}, \alpha_{s}\right)$ is called contract $S$, and $\left(m_{t}, \alpha_{t}\right)$, contract $T$.

\section{Contracts that induce settlement}

If firm $I$ wants the outcome to be a settlement, the contract $\left(m_{s}, \alpha_{s}\right)$ must be such that

- a settlement is preferred by firm $H$, i.e., $G_{H} \geq d_{H}$ or, equivalently, (12) must be satisfied;

- it insures the participation of each member. At this stage of the game, there is a probability $q$ of infringement and, therefore, each member chooses to participate if his expected payoff is not negative, i.e., $q G_{i}+(1-q) G_{i}=G_{i} \geq 0$, where $G_{i}$ is defined by equation (3).

Furthermore, we assume that when the members are indifferent between accepting the contract or refusing it, they always accept. Hence, the participation constraint for each member

\footnotetext{
${ }^{10}$ To be more realistic, we should assume that each member gets a different share of the profit, depending on how many consumers he has added. However, to keep the analysis simple, we assume they all get the same share.
} 
becomes $G_{i}=0$, which we can rewrite as

$$
\alpha=\frac{\gamma}{\Pi_{I}(m)}
$$

and thus, (12) becomes

$$
\Delta-\left(\Pi_{H}-\widetilde{\Pi}_{H}\right)+\Pi_{I}(m)-(1+\beta) m \gamma \geq 0
$$

Hence, there exists a value $\widetilde{m}_{s}>0$, such that $\Delta-\left(\Pi_{H}-\widetilde{\Pi}_{H}\right)+\Pi_{I}(m)-(1+\beta) m \gamma=0$, and then $m_{s}$ must satisfy $m_{s} \leq \widetilde{m}_{s}$. Furthermore, the cutoff value $\widetilde{m}_{s}$ is a function of $\beta$. Therefore, we denote this as cutoff value $\widetilde{m}_{s}(\beta)$. Let us define $\Sigma_{s}=\left\{\left(m_{s}, \alpha_{s}\right) / m_{s} \leq \widetilde{m}_{s}(\beta)\right.$ and $\left.\alpha_{s}=\gamma / \Pi_{I}(m)\right\}$, the set of contracts $S$.

Among all of the possible contracts $\left(m_{s}, \alpha_{s}\right) \in \Sigma_{s}$, firm $I$ chooses the contract that maximizes his expected payoff $G_{I}^{e}=\left\{q G_{I}+(1-q) g_{I}\right\}$, where $G_{I}$ is given by equation (2), $g_{I}$ by equation (8), and the license fee is defined by (11). Therefore, the optimal size of network $m_{s}^{*}(\beta)$ is the solution of

$$
\Pi_{I}^{\prime}(m)-\Phi_{s}(\beta) \gamma=0
$$

where $\Phi_{s}(\beta)=\left[2-q p_{H}\left(\rho+\beta_{I}\right)+q p_{H}(1-\rho) \beta\right] /\left[2-q p_{H}\left(\rho+\beta_{I}\right)\right]$, and must be such that $m_{s}^{*}(\beta) \leq \widetilde{m}_{s}(\beta)$. Notice that the optimal solution also depends on $\beta$. We summarize this contract in the following lemma:

Lemma 2 (Contract $S$ ) The optimal contract $\left(m_{s}^{*}(\beta), \alpha_{s}(\beta)\right)$ is such that

- the size of the network $m_{s}^{*}(\beta)$ is the solution of (13),

- $\operatorname{and}\left(m_{s}^{*}(\beta), \alpha_{s}(\beta)\right) \in \Sigma_{s}$.

Hence, for a given value of $\beta$, if there exists a unique $m_{s}^{*}(\beta)$ that satisfies $m_{s}^{*}(\beta)<\widetilde{m}_{s}(\beta)$, there exists a unique $\alpha_{s}(\beta)$ that defines the share of profit for each member.

\section{Contracts that induce trial}

On the other hand, if firm $I$ wants a trial to occur in case of infringement, the contract $\left(m_{t}, \alpha_{t}\right)$ must be such that 
- a trial is preferred by firm $H$, i.e., $G_{H}<d_{H}$, or equivalently, (12) must not be satisfied,

- and $q d_{i}+(1-q) g_{i} \geq 0$, to insure the participation of each member.

By the same token, using equations (6), (9) and (10), $q d_{i}+(1-q) g_{i}=0$ can be rewritten as

$$
\alpha=\Phi_{t}(\beta) \frac{\gamma}{\Pi_{I}(m)}
$$

where $\Phi_{t}(\beta)=\left(2-q p_{H}\right) /\left[2-q p_{H}(1+\beta)\right]$ and there exists $\widetilde{m}_{t}(\beta)$ such that $\Delta-\left(\Pi_{H}-\widetilde{\Pi}_{H}\right)+$ $\Pi_{I}(m)-(1+\beta) \Phi_{t}(\beta) m \gamma=0$, and then $m_{t}$ must satisfy $m_{t}>\widetilde{m}_{t}(\beta)$. Let $\Sigma_{t}=\left\{\left(m_{t}, \alpha_{t}\right) /\right.$ $m_{t}>\widetilde{m}_{t}(\beta)$ and $\left.\alpha_{t}=\Phi_{t}(\beta) \gamma / \Pi_{I}(m)\right\}$ be the set of contracts $T$.

Among all of the possible contracts $\left(m_{t}, \alpha_{t}\right) \in \Sigma_{t}$, firm $I$ chooses the contract that maximizes his expected payoff $d_{I}^{e}=\left\{q d_{I}+(1-q) g_{I}\right\}$, where $d_{I}$ is given by equation (5), $g_{I}$ is given by equation (8), and the penalty is defined in (10). The optimal size of network $m_{t}^{*}(\beta)$ is the solution of

$$
\Pi_{I}^{\prime}(m)-\Phi_{t}(\beta) \gamma=0
$$

and must be such that $m_{t}^{*}(\beta)>\widetilde{m}_{t}(\beta)$.

Lemma 3 (Contract $T$ ) The optimal contract $\left(m_{t}^{*}(\beta), \alpha_{t}(\beta)\right)$ is such that

- the size of the network $m_{t}^{*}(\beta)$ is the solution of (14),

- $\operatorname{and}\left(m_{t}^{*}(\beta), \alpha_{t}(\beta)\right) \in \Sigma_{t}$.

\section{Share of profit and size of network}

We find that the fraction that each member gets from participating in selling the good is higher when the outcome is a trial rather than a settlement $\left(\alpha_{t}>\alpha_{s}\right)$ for a given number of members $m$. Indeed, members need to be compensated for a potential trial. Furthermore, the larger the size of the network, the smaller the share of profit per member (as $\partial \alpha_{j} / \partial m<0$ for $j=s, t)$. The share is also affected by the level of contributory infringement in an obvious way when a settlement is reached $\left(\operatorname{sign}\left(\partial \alpha_{s} / \partial m\right)=-\operatorname{sign}(\partial m / \partial \beta)\right)$. On the other hand, the total number of members that will be in the network is affected by the outcome of the game. 
In the absence of the CI rule $(\beta=0)$, the optimal network size is not influenced by the possibility of indirect infringement and, thus, $m_{s}^{*}(0)=m_{t}^{*}(0)$. Indeed, the members' decisions to enter the network are not affected by the threat of a trial.

With contributory infringement $(\beta>0)$, the optimal size of the network is influenced by the possibility of indirect infringement, and depends on the outcome of the game if infringement occurs. The comparison of (13) and (14) is straightforward and leads to the following inequalities:

$$
m_{t}^{*}(\beta) \leq m_{s}^{*}(\beta) \leq m_{s}^{*}(0)=m_{t}^{*}(0),
$$

as $\Phi_{s}(\beta) \leq \Phi_{t}(\beta)$, with strict inequality for $\beta>0$ and equality for $\beta=0$.

We can posit the following lemma:

Lemma 4 The enforcement of the CI rule decreases the optimal network size, whether the outcome is a settlement or a trial. The network size is smaller in the case of trial.

When the CI rule is enforced, firm $I$ decreases the size of his network, even when a settlement is reached. Indeed, when the CI rule is enforced, the cost of an extra member is, in fact, the marginal license fee that the infringer has to pay to recruit another member. However, in the case of contributory infringement, the marginal license fee entails some of the payment made by the member in the case of a successful trial and, as a result, the marginal license fee is higher than without contributory infringement; therefore, fewer members will join the membership program.

\section{Optimal contracts and level of contributory infringement}

The feasibility of the contracts depends upon the level of contributory infringement. Indeed, contract $T$ as defined in lemma 3 is not feasible for small values of $\beta$. We can state the following result:

Lemma 5 (Contract feasibility) Contract $T$ is not feasible for relatively small levels of contributory infringement (i.e., $\beta<\widehat{\beta}_{1}$ ); there exists no optimal network size such that firm I can make firm $H$ prefer a trial. On the other hand, for relatively high levels of contributory infringement (i.e., $\beta \geq \widehat{\beta}_{1}$ ), both contracts are feasible. 
Proof. See appendix.

However, contract $S$ as defined in lemma 2 is always feasible, but for certain values of the contributory infringement parameter, firm $I$ must reduce his network size compared to the optimal size. This is summarized in the next lemma:

Lemma 6 (Network size) For small levels of contributory infringement (i.e., $\beta<\widehat{\beta}_{2}$ ), contract $S$ is always optimally chosen (i.e., $\left.m_{s}^{*}(\beta)\right)$. For relatively high levels of contributory in-

fringement (i.e., $\beta \geq \widehat{\beta}_{2}$ ), when offering contract $S$, firm $I$ is constrained to reduce his network size to $\widetilde{m}_{s}(\beta)$.

Proof. See appendix.

\section{Optimal Contract and Equilibrium Litigation Outcome}

We now define the subgame perfect Nash equilibrium when firm $I$ enters the market.

Proposition 1 The subgame perfect Nash equilibrium is such that

- for $\beta<\widehat{\beta}_{2}$, firm I offers the optimal contract $S$ that the members accept and the litigation outcome is a settlement;

- for $\beta \geq \widehat{\beta}_{2}$, firm I offers a constrained contract $S$ (i.e., $\left.\widetilde{m}_{s}(\beta)\right)$ that the members accept and the litigation outcome is a settlement.

Proof. See appendix.

Thus, for low levels of contributory liability, each of the $m_{s}^{*}(\beta)$ members gets a fraction $\alpha_{s}(\beta)$ of the profit of the infringer, and a settlement is reached in which the infringer pays a license fee to the patentholder. Members are not liable, even though their potential liability impacts on the choice of the license fee. For higher levels of contributory infringement, each of the $\widetilde{m}_{s}(\beta)$ members gets a fraction $\alpha_{s}(\beta)$ of the profit, and infringer and patentholder settle out-of-court again. Thus, firm $I$ prefers to insure that the outcome will be a settlement rather than a trial.

Following proposition 1 we can posit the following proposition. 
Proposition 2 Whether the CI rule is enforced or not, a settlement is always achieved. The higher the $\beta$, the smaller the network size.

As $\beta$ increases, we go from a regime in which a settlement is achieved without a constrained network size to a regime in which a settlement is achieved with a constrained network size. The network size is decreasing with $\beta$.

Thus, surprisingly higher levels of liability do not induce more trials in equilibrium, even though the threat of a trial decreases the network size. This is due to the fact that firm $I$ chooses the contract first, and thus has a first-mover advantage. Indeed, firm $I$ shapes the contract in such a way that firm $H$ always prefers a settlement over a trial. Furthermore, we have made the implicit and plausible assumption that whenever firm $H$ is indifferent between a trial and a settlement, he prefers a settlement. This is consistent with what we observe in reality: there are very few trials for contributory infringement.

\section{Welfare Analysis of Contributory Infringement}

In order to fully characterize the welfare effect of the CI rule, we need to specify the demand side more precisely. Let us consider that each consumer can consume one or zero units of the good per period. A consumer has the following utility function:

$$
U= \begin{cases}v-p & \text { if he buys the good at price } p \\ 0 & \text { otherwise }\end{cases}
$$

where $v$ represents the taste parameter of the consumer, and is distributed according to some density $f(v)$ and cumulative distribution function $F(v)$. Hence, $F(v)$ is the fraction of consumers with a taste parameter smaller than $v$, and the total demand at price $p$ is, therefore,

$$
D(p, m)=[1-F(p)] S(m),
$$

where $S(m)$ is the number of consumers, with $S^{\prime}(m)>0$ and $S^{\prime \prime}(m)<0$. The larger the network, the larger the consumer base. Furthermore, the number of consumers increases at a decreasing rate. With this specification of the demand, we can define more precisely the profit of firm $I$,

$$
\Pi_{I}(m)=(p-C)[1-F(p)] S(m),
$$


where $(p-C)$ represents the markup, with $C$ being the marginal cost of production. To keep the model simple and because we do not consider price setting, we do not really need the characterization of this profit function. However, this function is consistent with our assumption that the profit increases at a decreasing rate.

This specification is, however, interesting in defining the consumer surplus:

$$
C S(m)=\int_{p}^{\infty}[1-F(x)] S(m) d x .
$$

It increases at a decreasing rate with the number of members in the network. At the optimal size of the network, $m_{s}(\beta)=\min \left\{\widetilde{m}_{s}(\beta), m_{s}^{*}(\beta)\right\}$, the consumer surplus is a decreasing function of the level of contributory infringement, as

$$
\frac{\partial C S}{\partial \beta}=\frac{d S}{d m} \frac{d m_{s}(\beta)}{d \beta}<0,
$$

and thus, the higher the $\beta$ the lower the consumer surplus.

We now define the total social welfare depending on the outcome of the litigation process.

If the outcome of the litigation process is a settlement, the expected total welfare is $W_{s}(\beta)=$ $q\left(G_{H}+G_{I}+m_{s} G_{i}\right)+(1-q)\left(g_{H}+g_{I}+m_{s} g_{i}\right)+2 C S\left(m_{s}\right)$ or, equivalently

$$
W_{s}(\beta)=2 \widetilde{\Pi}_{H}-q c_{I}^{s}+2\left(\Pi_{I}\left(m_{s}\right)-\gamma m_{s}\right)+2 C S\left(m_{s}\right)
$$

Note that the license fee is just a transfer from firm $I$ to firm $H$ and has no impact on the social welfare.

If a trial occurs, the expected total welfare is $W_{t}(\beta)=q\left(d_{H}+d_{I}+m_{t} d_{i}\right)+(1-q)\left(g_{H}+g_{I}+\right.$ $\left.m_{t} g_{i}\right)+2 C S\left(m_{t}\right)$, which can be rewritten as

$$
W_{t}(\beta)=\left(2-q p_{H}\right) \widetilde{\Pi}_{H}+q p_{H} \Pi_{H}-q\left(c_{H}^{t}+c_{I}^{t}\right)+\left(2-q p_{H}\right)\left(\Pi_{I}\left(m_{t}\right)-\gamma m_{t}\right)+2 C S\left(m_{t}\right),
$$

where, again, the penalty paid is just a transfer from firm $I$, and each firm $i$ in case of liability, to firm $H$. We can thus posit the following proposition.

Proposition 3 (Welfare Effect) For a given level of damages, a regime with contributory infringement (i.e., $\beta>0$ ) always decreases the total welfare compared to a regime without (i.e., $\beta=0)$. For a given $\beta$, the total welfare is higher if a settlement occurs, $W_{s}(\beta)>W_{t}(\beta)$. 
Proof. See appendix.

This proposition shows that once the innovation is patented, the CI rule has only a negative impact on the total social welfare.

Our analysis of welfare shows that it is increased by simply removing contributory liability. However, we have been silent on who benefits when the degree of contributory liability $\beta$ is altered. Whenever infringement is not prevented, it is of interest to study how the patentholder's payoff is affected. Indeed, assuming that this payoff is a good proxy for the patentholder's ex ante incentive to invest in $\mathrm{R} \& \mathrm{D}$, we shall now discuss how sensitive this payoff is to a variation of $\beta$.

Proposition 4 (R\&D Incentives) The CI rule is preferred by the patentholder only if $0<$ $\beta<\bar{\beta}_{s}$. Moreover, there exists a unique $\beta_{s}^{*}$ such that the private incentives for RED are at a maximum. This level is characterized by $0<\beta_{s}^{*}<\bar{\beta}_{s}$.

Proof. See appendix.

This result may seem counterintuitive. Indeed, raising the level of damages that the patentholder can obtain when he wins the trial can make him worse off. This is due to the fact that a change in the value of $\beta$ has essentially two contradictory effects on the patentholder's payoff. A higher $\beta$ increases the level of damages per member obtained by the patentholder ex post, but it also tightens the participation constraint of the members. This results in a smaller infringer network, and damages will be collected from fewer members. The license fee negotiated by the patentholder will be smaller.

The reason for maximizing the amount of the patentholder's damages is formally identical to setting a monopoly price. A regulator or a judge willing to maximize the license fee would set $\beta=\beta_{s}^{*}$, such that the increased benefit of more damages (i.e., a higher price) is equal to the foregone profit of fewer members (i.e., of having fewer buyers).

It is also interesting to note that when $\beta>\bar{\beta}_{s}$ everyone (except the judge!) would prefer ex ante to waive the contributory liability. In such a case, not only is no contributory liability socially optimal (see proposition 3), but it is also Pareto optimal for all of the players. The next corollary completes proposition 4 . 
Corollary 1 At the equilibrium, any level of contributory infringement greater than $\beta_{s}^{*}$ but smaller than $\bar{\beta}_{s}$ is suboptimal.

Proof. See appendix.

The amount of damages received depends on parameter $\beta$. Our point is that any optimal level of $\beta$ set by a policy-maker should lie strictly in the interval $\left(0, \beta_{s}^{*}\right)$. A policy-maker may want to foster the ex ante incentives of the patentholder to do research, and in this case a $\beta$ close to but smaller than $\beta_{s}^{*}$ would be optimal. Conversely, the policy-maker may want to favor network end-users (i.e., consumers), and then would set $\beta$ close to 0 to maximize the network size. However, setting $\beta \in\left(\beta_{s}^{*}, \bar{\beta}_{s}\right)$ would decrease the network size and the total amount of damages received by the patentholder.

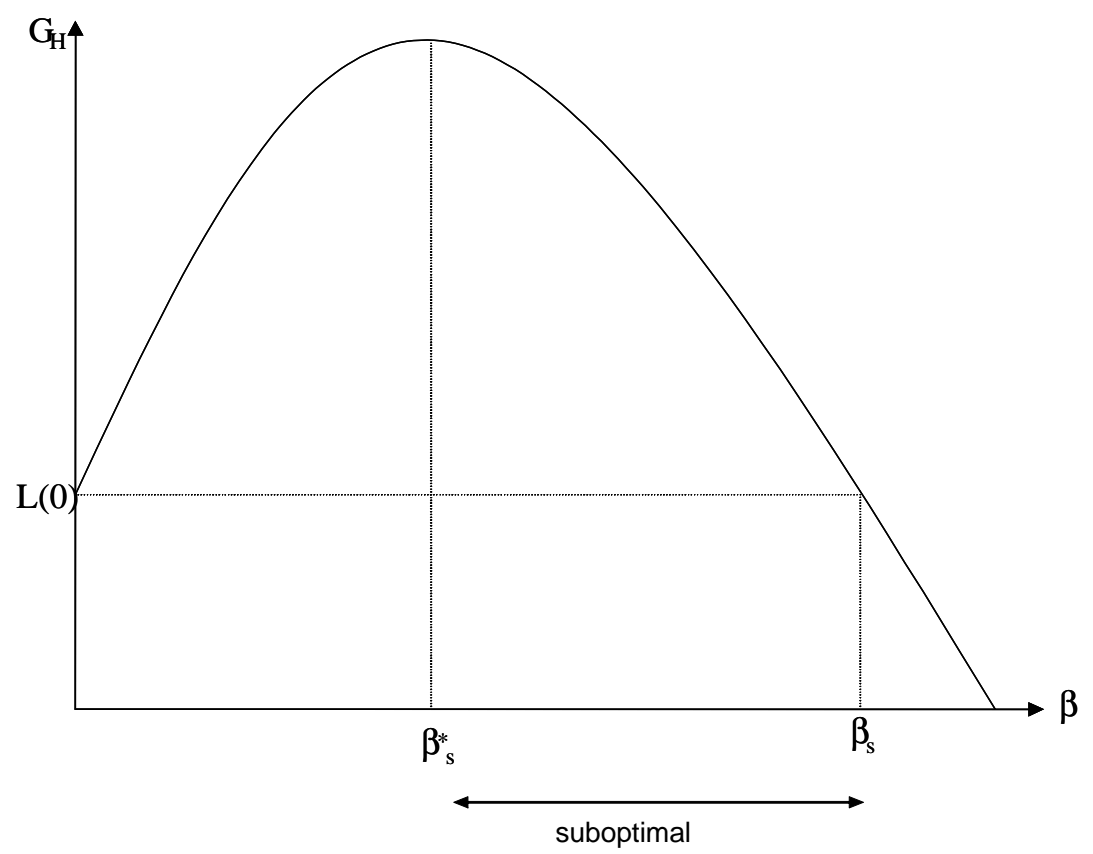

This result shows formally that tighter intellectual property protection can strictly decrease the incentive to innovate in a network setting. It is consistent with the analysis of Bessen and Maskin (2004), who argue that "moderately weak intellectual protection is optimal." However, they advocate weaker protection because it favors innovation through imitation. Our point is different, since we argue that the network structure helps to "transmit" infringement liability to all of the members, and makes them less inclined to join the network. 
The damages or the license awarded to the patentholder are important for judging his incentives to invest ex ante. When contributory liability exists, the amount of damages received by the patentholder is described by the parameters $\beta_{I}$ and $\beta$. Thus, the "weight of liability" is split between the infringer and the members. It is interesting to analyze whether one can generate the same amount of damages without contributory liability. The next corollary develops a result along these lines.

Corollary 2 Consider a given structure $B$ of direct and contributory infringement damages, with $\beta_{I}>0$ and $\beta>0$. There exists another structure $B^{\prime}$ characterized by $\beta_{I}^{\prime}>0$ and $\beta^{\prime}=0$, such that if infringement occurs, the level of the license fee is identical to that obtained with structure B. Structure $B^{\prime}$ is socially better than structure $B$.

Proof. See appendix.

Therefore, with a risk of infringement, it is possible to give the same incentive to invest in $\mathrm{R} \& \mathrm{D}$ ex ante with and without the CI rule, and a larger network is obtained ex ante. This result rather pleads for minimizing the liability of contributory infringers and increasing the liability of direct infringers when this is possible.

Our results can be compared with those of Hay and Spier (2005). Indeed, they show that, whenever possible, a manufacturer of a product should not be held responsible when a customer, while using the product, harms a third party. More precisely, they show that if the producer of the harmful good is held responsible, then he will choose to distort the quantity of the good offered on the market. A similar effect is at work in our framework. Indeed, if members are held responsible for indirect infringement, they might choose not to participate in the network, thereby reducing the social welfare.

It is worth noting that in all of our previous analyses we assumed the entry of firm $I$. However, as mentioned in the presentation of the model, the potential infringer has to decide whether to enter or not. 


\section{Extensions}

We now discuss and/or relax some of the assumptions of our model. First, we discuss the entry decision of the potential infringer. Second, we take into account that indirect trials are expensive and show that our main findings still hold. Third, we analyze a situation in which the members have a more active role in the bargaining process. Indeed, we allow them to be involved in a litigation process with the patentholder once the direct infringer has been found guilty of infringement, and we show that our results still hold. Fourth, we discuss contracts between the infringer and the members. Lastly, we present how our model could apply to settings different from e-commerce.

\subsection{Entry and Level of Direct Damages}

The decision to enter is made at the beginning of the game and depends on whether the expected profit of the infringer $G_{I}^{e}=q G_{I}+(1-q) g_{I}$ is positive. The next result discusses the occurrence of entry as a function of direct and indirect damages.

Proposition 5 Entry with a risk of infringement occurs when direct and indirect damages $\left(\beta_{I}, \beta\right)$ are such that $\beta_{I}<\bar{\beta}_{I}(\beta)$, where $\bar{\beta}_{I}(\beta)$ is decreasing in $\beta$.

Proof. See appendix.

Not surprisingly, whether entry occurs or not is simply a matter of how harsh the punishment of the direct infringer is, as he is at risk of infringing. In other words, setting a high level of $\beta_{I}$ makes infringement less likely. It is rather intriguing that an increase in contributory liability has a first-order effect on the entry decision, and therefore on the infringement; that is, an increase of $\beta_{I}$ has an effect qualitatively equivalent to an increase of $\beta$. This result is due to the settlement outcome. Indeed, if the outcome is a trial, an analysis of $d_{I}^{e}=q d_{I}+(1-q) g_{I}$ shows that increasing $\beta$ would affect the infringer's decision only through the network's size. With a settlement, a higher $\beta$ directly increases the level of the license fee. Therefore, from a public standpoint, $\beta_{I}$ and $\beta$ cannot be chosen independently as far as infringement is concerned.

However, in our model, the objective of a lawmaker is not necessarily to always prevent risky entry, as it is, by assumption, not socially desirable. Indeed, as members and end-users benefit 
from the (infringing) innovation, infringement increases social welfare. The relevance of this assumption can be discussed in a more general context. For instance, when there is a great deal of uncertainty about the future value of an innovation, it may be optimal to let the infringement occur, and then eventually sanction it, once uncertainty has disappeared. ${ }^{11}$ This "laissez-faire" policy allows for the introduction of valuable innovations that might otherwise not exist if, for instance, a simple injunction was enforced (Lemley and Reese, 2004). ${ }^{12}$

In addition to uncertainty, in some cases $R \& D$ costs are known to be small, and (too) strong IPRs are not needed, since adequate incentives to innovate are easily obtained. Many innovations related to digital networks, such as patented business-method software, fall into that category (Rivette and Kline, 2000). Therefore, when the infringing innovation generates enough (transferable) surplus to cover the $\mathrm{R} \& \mathrm{D}$ costs of the original innovator, infringement is then more desirable.

The next corollary extends the findings of corollary 2 when the entry decision is taken into account.

Corollary 3 Assuming that entry, and possibly infringement, are socially desirable and that the structure of damages $B$ satisfies $\beta_{I}<\bar{\beta}_{I}(\beta)$ (i.e., entry occurs), there always exists a structure $\bar{B}$ of liability levels such that

1. entry still occurs with the same level of license fee;

2. the network is strictly wider.

Proof. See appendix.

\footnotetext{
${ }^{11}$ Note that this could be incorporated into our model by introducing some uncertainty on consumer tastes; this uncertainty would later be resolved.

${ }^{12}$ The "Sony-Betamax" case (i.e., Sony v. Universal City Studios, Inc., 464 U.S. 417 (1984)) illustrates this dilemma well. In 1976, the U.S. Supreme Court ruled that the introduction by Sony of the Betamax VCR did not constitute an act of (contributory) infringement, although it gave users the possibility of recording television programs that were copyrighted. In the spirit of patent law, the Court ruled that, since the VCR was capable of being used for "commercially significant non-infringing" purposes, Sony would not be held responsible for contributory infringement. Retrospectively, judges were arguably right to rule in favor of Sony, since later this innovation would benefit even Universal.
} 
This result states that lowering the liability of indirect infringers, while keeping incentives for R\&D constant through identical levels of license fees, may be achieved without changing the entry decision. In fact, doing so is optimal from a social standpoint. The logic for this result goes as follows. Although the negotiation between the infringer and the patentholder is a zero-sum game, the lawmaker strictly increases the surplus to be divided by transferring as much as possible liability from the members to the infringer.

To understand the total effect of a change in damage structure, it is worth decomposing it into two effects. First, a decrease of the indirect liability makes the infringer better off as the network grows, but makes the patentholder worse off as the license fee is reduced. This is the indirect liability effect. Second, to keep the R\&D incentives constant, the direct liability must be increased, which makes the infringer worse off.

\subsection{Indirect Trial Cost}

We now investigate the impact of the introduction of a patentholder indirect trial cost. Our model assumes that it is costless for the patentholder to launch lawsuits against members once the direct infringer has been found guilty of infringement. However, in reality, since the patentholder would have to prove intent on the part of each contributory infringer, lawsuits might be expensive. Thus, we introduce a trial $\operatorname{cost} c^{t}$ that the patentholder has to incur to launch a lawsuit against each of the members. Therefore, the total cost is $m c^{t}$, to be included in the profit function (4) as long as $\beta>0$. The introduction of this trial cost has an impact on equation (12) that becomes

$$
\Delta-\left(\Pi_{H}-\widetilde{\Pi}_{H}\right)+\Pi_{I}(m)-(1+\beta) \alpha m \Pi_{I}(m)+\frac{1}{\rho} m c^{t} \geq 0 .
$$

In the rest of the analysis, all of the threshold values are affected, but in the same way. For instance, in the case of settlement, instead of having a value $\widetilde{m}_{s}(\beta)$ such that $\Delta-\left(\Pi_{H}-\widetilde{\Pi}_{H}\right)+$

$\Pi_{I}(m)-(1+\beta) m \gamma=0$, we now have a value $\widetilde{m}_{s}^{\prime}(\beta)$ such that $\Delta-\left(\Pi_{H}-\widetilde{\Pi}_{H}\right)+\Pi_{I}(m)-(1+$ $\beta) m \gamma+m c^{t} / \rho=0$, where $\widetilde{m}_{s}^{\prime}(\beta)>\widetilde{m}_{s}(\beta)$. Similarly, in the trial case, we now have $\widetilde{m}_{t}^{\prime}(\beta)$ such that $\Delta-\left(\Pi_{H}-\widetilde{\Pi}_{H}\right)+\Pi_{I}(m)-(1+\beta) \Phi_{t}(\beta) m \gamma+m c^{t} / \rho=0$, where $\widetilde{m}_{t}^{\prime}(\beta)>\widetilde{m}_{t}(\beta)$. Overall, the comparisons of all of the optimal network sizes are identical and, therefore, we still obtain the same qualitative results. In fact, making trials more expensive for the patentholder increases 
his incentive to settle out-of-court.

\subsection{Sequential Bargaining Process}

In our model, the members have a passive role, as they do not participate in the bargaining process. They are all sued by the patentholder in the case of a successful trial against the infringer. However, it may be the case that the members and the patentholder engage in a litigation process once the patentholder wins. We now explore this case and determine how our findings are affected when members are involved in a negotiation process with the patentholder.

In the case of a successful trial against the direct infringer, we explore the litigation process between the patentholder and the indirect infringers. We assume that the patentholder bargains with all of the members simultaneously or with a representative member (since they are all identical, there is no loss of generality). We find that the patentholder and the members prefer to settle out-of-court and the license fee paid by each member is $L_{i}=p \beta \alpha \Pi_{I}(m)+\delta_{i}-c^{t}$, where $p$ is the probability that the patentholder wins the case against the members (that can eventually be equal to $\left.p_{H}\right), \delta_{i}=\rho_{i}\left(c_{i}^{t}+c^{t}-c_{i}^{s}\right), c_{i}^{s}$ is the settlement cost for the members, $c^{t}$ is the trial cost borne by firm $H$, and $c_{i}^{t}$ the trial cost borne by each member.

If a settlement occurs with the direct infringer, the payoffs of the patentholder, the infringer and each member are

$$
\begin{aligned}
G_{H}^{s} & =2 \widetilde{\Pi}_{H}+L^{s}, \\
G_{I}^{s} & =2(1-\alpha m) \Pi_{I}(m)-L^{s}-c_{I}^{s}, \\
G_{i}^{s} & =2\left(\alpha \Pi_{I}(m)-\gamma\right),
\end{aligned}
$$

where the superscript $s$ stands for settlement with members, and $L^{s}$ is the license fee that is paid by the infringer when the threat point is a trial with the direct infringer, potentially followed by a settlement with the members.

In the case of trial, the payoffs are

$$
\begin{aligned}
d_{H}^{s} & =\left(2-p_{H}\right) \widetilde{\Pi}_{H}+p_{H} \Pi_{H}-c_{H}^{t}+p_{H} R_{H, I}+p_{H} m L_{i}-p_{H} m c^{s}, \\
d_{I}^{s} & =\left(2-p_{H}\right)(1-\alpha m) \Pi_{I}(m)-c_{I}^{t}-p_{H} R_{H, I}, \\
d_{i}^{s} & =\left(2-p_{H}\right)\left(\alpha \Pi_{I}(m)-\gamma\right)-p_{H} L_{i}-p_{H} c_{i}^{s} .
\end{aligned}
$$


The license fee between the patentholder and the direct infringer is now

$$
\begin{aligned}
L^{s}= & p_{H} \Pi_{I}(m)\left[(1-\alpha m)\left(\rho+\beta_{I}\right)+(1-\rho) p \beta \alpha m\right]+(1-\rho) p_{H} m\left(\delta_{i}-c^{t}\right) \\
& +(1-\rho) p_{H}\left(\Pi_{H}-\widetilde{\Pi}_{H}\right)+\rho\left(c_{I}^{t}-c_{I}^{s}\right)-(1-\rho) c_{H}^{t} .
\end{aligned}
$$

Taking into account these changes in the different payoffs, we can redefine the specific contracts $S$ and $T$. We find that the previous results are not qualitatively affected by these changes. However, unlike the model developed in sections 4 and 5, here we do not assume that the first trial (against the infringer) is always followed by other trials for contributory infringement; rather, the patentholder and the members can (and will, indeed) choose to settle out-of-court. Thus, the patentholder has weaker incentives to reach an agreement at the first stage, as this will not adversely impact network size.

\subsection{Indirect infringement and Other Contractual Arrangements}

In our analysis, we have been silent about the exact links between the infringer and the members. The nature of this relationship is likely to impact our model and, in particular, the nature of the contract between the infringer and the members. If the members are subsidiaries/parent companies of the infringer, then the profit sharing contract that we propose may no longer be (privately) optimal for the infringer. For instance, a contract contingent on the occurrence of a lawsuit may fare better; it would specify that all of the profits would be transferred to the members if a lawsuit arose or was likely to arise. This contract would essentially render the infringer judgment-proof, leaving the patentholder with an "empty shell." In our context, any incentive to sue the infringer in the first place would be reduced.

The effectiveness of this "strategic" contract is, however, sensitive to the strict enforcement of the limited liability principles of common law that explicitly protect corporation owners from legal suit launched against subsidiaries on the basis that the parent corporation does not "operate" the subsidiary. However, the law has broadened the definition of operation and extended liability in many instances (for examples, see Boyd and Ingberman, 2003). In our context, extending liability would simply nullify the effect of such a strategic payment scheme and our results would still hold. 
We also assume that the infringer is unable to fully insure members against contributory infringement lawsuits. Indeed, one possibility is for the infringer to pay for any network connection costs and commit to indemnify members for intellectual property claims raised against them. With such a commitment, the infringer would internalize the externalities caused by indirect infringement and restore the efficient network size.

However, the "commitment case" relies on assumptions that may not be true in our context. First, the infringer cannot be bankrupted or insolvent after losing the trial, which may be the case if, for instance, the infringer has to pay high punishment damages, that is $\beta_{I}>1$. Second, this contract, like any insurance contract, creates moral hazard frictions the level of which must remain low for it to be feasible. Indeed, since members do not face any damages for behaving "as if they knew about" their infringing activity, proving intent will be easier. Another potential problem with this contract is that the parties involved are no longer adversarial, and this creates clear incentives for "side contracting" between the patentholder and the members. Of course, the contract could be amended in ways that prevent these devious incentives, but it is no longer clear whether these amendments would be distortion-free. ${ }^{13}$ Thus, we believe that focusing on the case where member participation is induced ex ante seems more realistic.

\subsection{Settings Other than E-Commerce}

More broadly, our model could apply to settings other than e-commerce whenever infringement and indirect infringement occur in the presence of network effects. Let us develop another setting that will lead to the same model and findings. Consider a firm that makes a product protected by a patent (or copyright or trademark) without the permission of the patentholder. This firm signs leases with various landlords to get retail space. After the product is sold, the

\footnotetext{
${ }^{13}$ The firm ORACLE has recently started to offer to indemnify its membership network of LINUX developers against intellectual property infringement claims that they could face using programs furnished by ORACLE. Perhaps not surprisingly, this help is conditional upon ORACLE getting "sole control of the defense and any settlement negotiations" and to ORACLE being given access to the "Information, authority, and assistance it needs to defend against or settle the claim." Although this example does not straightforwardly apply to our setting, our aim is to point out potential important distortions created by these rather stringent conditions (http://www.oracle.com/technologies/linux/ubl-faq.pdf accessed 22/12/2006).
} 
patentholder detects infringement and either sues the infringer or grants him a license. The contributory infringement doctrine allows the patentholder to sue the landlords, as well. In this slightly different setting, we could reinterpret our findings in terms of number of leases and rental rates, and therefore, show that at the equilibrium the number of leases is reduced and settlement will occur more often.

\section{Conclusion}

In this paper we consider a network innovation, and we study the effects of the CI rule on the size of a network of members and on total social welfare. We do not address whether e-commerce patents should be granted; rather, we investigate the impact of the CI rule on this particular kind of patent. We show that whether firms settle out-of-court or go to trial, the optimal size of the network is smaller when the CI rule is enforced. This decreases total social welfare. At the equilibrium, firms settle out-of-court, no matter the level of contributory infringement. Furthermore, we show that even if the patentholder can receive the same compensation under both regimes (with and without contributory infringement), network size is still smaller under the CI rule. This rule is harmful to society when some infringement is desirable. Therefore, we question the relevance of such a rule in the case of e-commerce patents.

Although we discuss the license fee received by the patentholder, we do not consider per se the $R \& D$ investment decision. This aspect is motivated by the fact that network innovations such as business methods are known to be costless to produce, and thus, our model represents a valid scenario for these innovations. Nevertheless, we believe that an R\&D stage could easily be added to our game in order to consider situations in which R\&D investments are substantial.

Finally, our model features one infringer and several contributory infringers. Our choice has been made essentially for expositional simplicity. However, we acknowledge that in many situations there might be one contributory infringer and several direct infringers. A variant of our model could be built to investigate this issue. 


\section{References}

[1] Aoki, R. and J.L. Hu. "A Cooperative Game Approach to Patent Litigation, Settlement and Allocation of Legal Costs," working paper 186, University of Auckland (1999).

[2] Bessen, J. and R. Hunt. "An Empirical Look at Software Patents," working paper 03-17/R, Federal Reserve Bank of Philadelphia (2004).

[3] Bessen, J. and E. Maskin. "Sequential Innovation, Patents and Imitation," working paper, MIT (2004).

[4] Blair, R. and T. Cotter. "An Economic Analysis of Seller and User Liability in Intellectual Property Law," University of Cincinnati Law Review, 1-45 (1999).

[5] Boldrin, M. and D. Levine. "Why Napster is Right," (2003).

[6] Boyd, J. and D. Ingberman. "Fly by Night or Face the Music? Premature Dissolution and the Desirability of Extended Liability," American Law and Economics Review (2003).

[7] Crampes, C. and C. Langinier. "Litigation and Settlement in Patent Infringement Cases," RAND Journal of Economics, 33:228-274 (2002).

[8] Daughety, A. Settlement (Bouckaert, b. and g degeest Edition), 95-158. Encyclopedia of Law and Economics, Edward Elgar Publishing Co., 2000.

[9] Daughety, A. and J. Reinganum. "Economic Theories of Settlement Bargaining," Annual Review of Law and Social Sciences, Vol. 1 (2005).

[10] Hay, B. and K. Spier. "Manufacturer Liability for Harm Caused by Consumers to Others," American Economic Review, 95:1700-1711 (2005).

[11] Jong, S.J. "Contributory Infringement of Patents in Korea," Washington University Journal of Law and Policy, 2:287-307 (2000).

[12] Kaplow, L. and S. Shavell. "Accuracy in the Assessment of Damages," Journal of Law and Economics, XXXIX:191-210 (1996). 
[13] Landes, W. and D. Lichtman. "Indirect Liability for Copyright Infringement: Napster and Beyond," Journal of Economic Perspectives, 17:113-124 (2003).

[14] Lemley, M. "Inducing Patent Infringement," U.C. Davis Law Review, 39(1):225-247 (2005).

[15] Lemley, M. and R. A. Reese. "Reducing Digital Copyright Infringement Without Restricting Innovation," Stanford Law Review, 56 (2004).

[16] Merges, R. "As Many as Six Impossible Patents Before Breakfast: Property Rights for Business Concepts and Patent System Reform," Electronic Commerce Symposium, 14:578615 (1999).

[17] Meurer, M.J. "The Settlement of Patent Litigation," RAND Journal of Economics, 20 (1):77-91 (1989).

[18] Rivette, K. and D. Kline. Rembrandts in the Attic: Unlocking the Hidden Value of Patents. Harvard Business School Press, 2000.

[19] Schankerman, M. and S. Scotchmer. "Damages and Injunctions in Protecting Intellectual Property," RAND Journal of Economics, 32:199-220 (2001).

[20] Shapiro, C. "Navigating the Patent Thicket: Cross Licensing, Patent Pools, and StandardSetting," Innovation Policy and the Economy, A. Jaffe, J. Lerner and S. Stern, Eds., Vol. 1. Cambridge, MA: MIT press, 119-150 (2001).

[21] Shapiro, C. "Antitrust Limits to Patent Settlements," RAND Journal of Economics, 34:391-411 (2003).

[22] Spier, K. Litigation (Polinsky m. and s. shavell Edition), chapter 4. The Handbook of Law and Economics, 2005.

[23] Warshofsky, F. The Patent Wars. New York: John Wiley and Sons, 1994. 


\section{Appendix}

\section{Structure of the network}

We describe an example of the structure of a membership program. The infringer, called firm $I$, has a program with $m$ members. For the sake of simplicity we will call this program the network of the infringer.

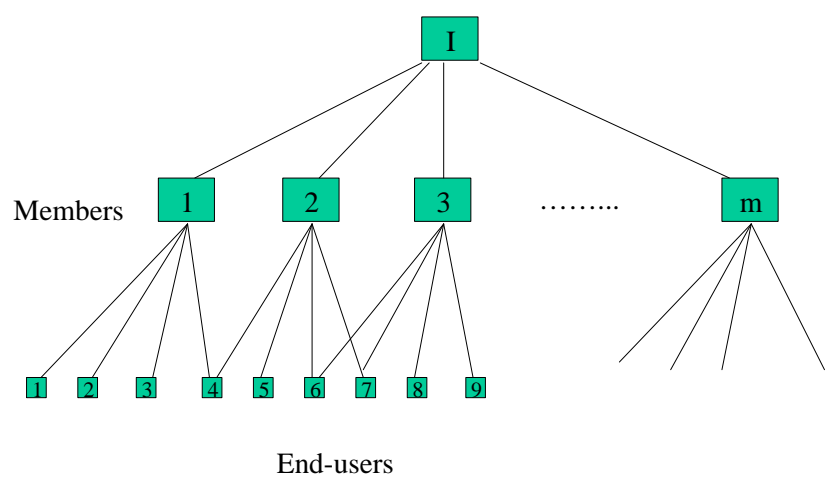

Figure 1: Network structure

Each member $i$ has $n$ end-users. There is a possibility of overlapping. An end-user who is connected to member 1 can also be connected to member 2 , and so on. Let $N(>n)$ be the total fixed number of end-users that represents the size of the total network.

The infringer chooses to have as many end-users (i.e., potential buyers) as possible. Every time he accepts a new member, there will be at most $n$ new end-users; at most, because among the new customers (i.e., end-users) some may already be connected to another member of the network. Consider the following trivial situation. The day he creates his membership program, the infringer does not have any members, consequently there are no end-users from his program. He accepts a new member (member 1 ) with $n$ new end-users. ${ }^{14}$ Then he accepts another member (member 2) with new end-users, as well. Some, if not all, of the end-users of member 2 can also

\footnotetext{
${ }^{14}$ This is, in fact, equivalent to a sampling without a replacement. Indeed, it is as if the infringer "draws" the first member from a set of members. This first member brings $n$ new end-users; i.e., $n$ times the proportion of end-users not yet connected to a member $((N-0) / N)$, which is 1 for the first member.
} 
be connected to member 1 . Therefore, the number of new ${ }^{15}$ end-users will be smaller or equal to $n$. Formally, let $G_{i}$ be the set of end-users who are not yet connected to a member that belongs to the network of the infringer when member $i$ joins the program. First, the infringer chooses member 1 with $n$ end-users. Second, he chooses another member (member 2) with $n G_{2} / N$ new end-users, where $G_{2}=N-n$. The third member will bring fewer new end-users, namely $n G_{3} / N$, where $G_{3}=N-n-n(N-n) / N$, and consequently the number of new end-users that member 3 brings is $n(N-n)^{2} / N^{2}$, and so on. To simplify the notation, let us denote $A=(N-n) / N$. With $m$ members in his network, the number of end-users will be ${ }^{16}$

$$
S(m)=n \frac{1-A^{m}}{1-A} .
$$

The number of end-users increases with the number of members at a decreasing rate $\left(S^{\prime}(m)>\right.$ 0 , and $\left.S^{\prime \prime}(m)<0\right)$.

\section{Proof of lemma 5 (Contract feasibility)}

The functions $\widetilde{m}_{s}(\beta), \widetilde{m}_{t}(\beta), m_{s}^{*}(\beta)$ and $m_{t}^{*}(\beta)$ are decreasing with $\beta$. It is easy to check that $\widetilde{m}_{s}(\beta) \geq \widetilde{m}_{t}(\beta)$ and $m_{s}^{*}(\beta) \geq m_{t}^{*}(\beta)$, with strict inequality for $\beta>0$ and equality for $\beta=0$. Furthermore, $\widetilde{m}_{s}(0)=\widetilde{m}_{t}(0)>m_{s}^{*}(0)=m_{t}^{*}(0)$. Let $\widehat{\beta}_{1}>0$ be the value of $\beta$ for which $m_{t}^{*}(\beta)=\widetilde{m}_{t}(\beta)$. According to lemma 4 , the optimal contract $T$ is such that $m_{t}>\widetilde{m}_{t}(\beta)$. Hence, for values smaller than $\widehat{\beta}_{1}, m_{t}^{*}(\beta)<\widetilde{m}_{t}(\beta)$ and, thus, a trial can never be preferred by firm $H$. However, for values greater than $\widehat{\beta}_{1}, m_{t}^{*}(\beta)>\widetilde{m}_{t}(\beta)$ is always satisfied and the contract is feasible.

\section{Proof of lemma 6 (Network size)}

Let $\widehat{\beta}_{2}>0$ be the value of $\beta$ for which $m_{s}^{*}(\beta)=\widetilde{m}_{s}(\beta)$. According to lemma 3 , the optimal contract $S$ is such that $m_{s} \leq \widetilde{m}_{s}$. Hence, for $\beta<\widehat{\beta}_{2}, m_{s}^{*}(\beta)<\widetilde{m}_{s}(\beta)$ and, thus, firm $I$ chooses the optimal network size. However, for $\beta \geq \widehat{\beta}_{2}, m_{s}^{*}(\beta)>\widetilde{m}_{s}(\beta)$ and, therefore, if firm $I$ wants the outcome to be a settlement, he needs to reduce his network size to $\widetilde{m}_{s}(\beta)$.

\section{Proof of proposition 1}

\footnotetext{
15 "New" meaning end-users not yet connected to the network of the infringer.

${ }^{16}$ It is easy to check that $S(m)=n+n\left(\frac{N-n}{N}\right)+n\left(\frac{N-n}{N}\right)^{2}+\ldots+n\left(\frac{N-n}{N}\right)^{m-1}$ is equivalent to $S(m)=$ $n \frac{1-\left(\frac{N-n}{N}\right)^{m}}{1-\left(\frac{N-n}{N}\right)}$.
} 
According to lemma 6 , for $\beta<\widehat{\beta}_{1}$, only contract $S$ is feasible. If $\widehat{\beta}_{2} \leq \widehat{\beta}_{1}$, for values of $\beta \in$ $\left[\widehat{\beta}_{2}, \widehat{\beta}_{1}\right]$ the only possible contract is the constrained contract $S$. For $\beta \geq \widehat{\beta}_{1}$, as both contracts can be offered, firm $I$ will choose the contract that maximizes his profit, i.e., $\max \left\{d_{I}^{e}, G_{I}^{e}\right\}$ where $d_{I}^{e}=\left\{q d_{I}+(1-q) g_{I}\right\}$ and $G_{I}^{e}=\left\{q G_{I}+(1-q) g_{I}\right\}$. This is equivalent to $\max \left\{d_{I}, G_{I}\right\}$. It is easy to show that, for any $m, G_{I}>d_{I}$, and therefore, $G_{I}^{e}>d_{I}^{e}$. Thus, it is also true when $G_{I}^{e}$ is determined at the optimal value $m_{s}^{*}(\beta)$ and $d_{I}^{e}$ at the optimal value $m_{t}^{*}(\beta)$. Thus, if $\widehat{\beta}_{2}>\widehat{\beta}_{1}$, for values of $\beta \in\left[\widehat{\beta}_{1}, \widehat{\beta}_{2}\right]$ the optimal contract $S$ is offered. If $\widehat{\beta}_{2} \leq \widehat{\beta}_{1}$, for $\beta \geq \widehat{\beta}_{1}$ the constrained contract $S$ is still preferred to the optimal contract $T$, as $\widetilde{m}_{s}(\beta)>m_{t}^{*}(\beta)$, and therefore, $G_{I}^{e}$ evaluated at $\widetilde{m}_{s}(\beta)$ is bigger than $d_{I}^{e}$, even at the optimal value $m_{t}^{*}(\beta)$.

\section{Proof of proposition 3}

The derivative of $W_{s}(\beta)$ with respect to $\beta$ is $\left(d \Pi_{I} / d m-\gamma+d S / d m\right) d m_{s}(\beta) / d \beta$, where $d \Pi_{I} / d m-\gamma>0$, as $d \Pi_{I} / d m-\Phi_{s}(\beta) \gamma=0$ at $m_{s}^{*}$ and $\Phi_{s}(\beta)>1$. Furthermore, as $d m_{s}(\beta) / d \beta<0$, then $\partial W_{s}(\beta) / \partial \beta<0$. In the same vein, we can show that

$$
\frac{\partial W_{t}(\beta)}{\partial \beta}=\left(\frac{d \Pi_{I}}{d m}-\gamma+\frac{d S}{d m}\right) \frac{d m_{s}(\beta)}{d \beta}-q p_{H}\left(\frac{d \Pi_{I}}{d m}-\gamma\right) \frac{d m_{s}(\beta)}{d \beta}<0 .
$$

It is also easy to verify that $\partial W_{t}(\beta) / \partial \beta>\partial W_{s}(\beta) / \partial \beta$.

\section{Proof of proposition 4 and corollary 1}

Let us denote by $\Delta B_{H}^{j}$ for $j=s, t$ the patentholder's profit difference when there is contributory liability and when there is not. When the outcome is a trial, $\Delta B_{H}^{t}=d_{H}(\beta)-d_{H}(0)$ which we can rewrite as

$$
\Delta B_{H}^{t}(\beta)=p_{H}\left[\beta_{I}\left(\Pi_{I}(\beta)-\Pi_{I}(0)\right)-m_{t}^{*}(\beta) \Phi_{t}(\beta)\left(\beta_{I}-\beta\right) \gamma+\beta_{I} \alpha_{t}(0) m_{t}^{*}(0) \Pi_{I}(0)\right],
$$

where $\Pi_{I}(\beta)=\Pi_{I}\left(m_{t}^{*}(\beta), \alpha_{t}(\beta)\right)$ for $\beta \geq 0$.

When $\beta=0$, i.e., in case of non-contributory infringement, $\Delta B_{H}^{t}=0$.

The derivative of $\Delta B_{H}^{t}$ with respect to $\beta$ can be simplified to

$$
\frac{\partial \Delta B_{H}^{t}}{\partial \beta}=\Phi_{t}(\beta) p_{H} c\left(m_{t}^{*}(\beta) \Phi_{t}+\beta \frac{d m_{t}^{*}(\beta)}{d \beta}\right),
$$

where $d m_{t}^{*}(\beta) / d \beta<0$. For $\beta=0$ the derivative is positive. However, for $\beta>0$ we cannot conclude. Let us study the function $\Phi_{t}(\beta)=\left(2-q p_{H}\right) /\left[2-q p_{H}(1+\beta)\right]$. It is an increasing and 
convex function with an asymptote at $\beta_{a}=\left(2-q p_{H}\right) / q p_{H}$. Indeed, $\lim _{\beta \rightarrow \beta_{a}} \Phi_{t}(\beta)=+\infty$. Using this, we can easily derive that $\lim _{\beta \rightarrow \beta_{a}} \Delta B_{H}^{t}=-\infty$. Thus, the function $\Delta B_{H}^{t}(\beta)$ is first increasing, starting from 0 , and then will eventually decrease. Thus, starting from 0 and increasing $\beta$ yields a higher benefit for the patentholder when contributory liability exists. Therefore, there exists a value of $\beta, \bar{\beta}_{t}$ that satisfies $\bar{\beta}_{t}>\beta_{t}^{*}>0$, and such that $\Delta B_{H}^{t}=0$ for $\beta=\bar{\beta}_{t}$ and $\Delta B_{H}^{t}$ is at a maximum for $\beta=\beta_{t}^{*}$, where $\beta_{t}^{*}=\arg \left(\frac{\partial}{\partial \beta} d_{H}(\beta)=0\right)$.

When the outcome is a settlement, the difference in profit is $\Delta B_{H}^{s}=G_{H}(\beta)-G_{H}(0)$, which can be reduced to

$$
\Delta B_{H}^{s}=L^{N B S}(\beta)-L^{N B S}(0)
$$

When $\beta=0, \Delta B_{H}^{s}=0$. The derivative of $\Delta B_{H}^{s}$ with respect to $\beta$ is zero, but the derivative of $L^{N B S}(\beta)$,

$$
\left.\frac{\partial L^{N B S}(\beta)}{\partial \beta}=p_{H}\left(\rho+\beta_{I}\right) \frac{\partial \Pi_{I}(\beta)}{\partial \beta}-p_{H} \gamma \frac{d m_{s}^{*}(\beta)}{d \beta}\left(\rho(1+\beta)+\left(\beta_{I}-\beta\right)\right)+p_{H} c m_{s}^{*}(\beta)(1-\rho)\right) .
$$

For $\beta=0, \partial L^{N B S}(\beta) / \partial \beta>0$. Furthermore, the second order condition

$$
\left.\frac{\partial^{2} L^{N B S}(\beta)}{\partial \beta^{2}}=p_{H}\left(\rho+\beta_{I}\right) \frac{\partial^{2} \Pi_{I}(\beta)}{\partial \beta^{2}}-p_{H} \gamma \frac{d^{2} m_{s}^{*}(\beta)}{d \beta^{2}}\left(\rho(1+\beta)+\left(\beta_{I}-\beta\right)\right)+2 p_{H} \gamma \frac{d m_{s}^{*}(\beta)}{d \beta}(1-\rho)\right)
$$

is negative if we assume that $d^{2} m_{s}^{*}(\beta) / d \beta^{2} \geq 0$. This implies that we need to put more structure on the function $\Pi_{I}(m)$. Thus, there exists a level of $\beta>0, \beta_{s}^{*}$, such that $\Delta B_{H}^{s}$ reaches a maximum, as the function is first increasing and concave. There also exists $\bar{\beta}_{s}>0$ such that $\Delta B_{H}^{s}\left(\bar{\beta}_{s}\right)=0$.

\section{Proof of corollary 2}

The structure $B^{\prime}$ (where $\beta_{I}^{\prime}>0$ and $\beta=0$ ) is such that the compensation received by the patentholder under both regimes is identical. At the equilibrium, the outcome is a settlement, and therefore, the optimal level of license fee received under the non-CI rule, $L^{N B S}\left(0, \beta_{I}^{\prime}\right)$, must be equal to the level of the license fee under the CI rule, $L^{N B S}\left(\beta, \beta_{I}\right)$. Let us denote $m_{s}^{*}\left(\beta, \beta_{I}\right)$ the optimal network size under the CI rule, and $m_{s}^{*}(0)$ under no CI rule, since the optimal size does not depend on $\beta_{I}$ anymore. Hence, the value of $\beta_{I}^{\prime}$ that satisfies

$$
L^{N B S}\left(0, \beta_{I}^{\prime}\right)=L^{N B S}\left(\beta, \beta_{I}\right)
$$


is

$$
\beta_{I}^{\prime}=\frac{\left(\Pi_{I}\left(m_{s}^{*}\left(\beta, \beta_{I}\right)\right)-\gamma m_{s}^{*}\left(\beta, \beta_{I}\right)\right)\left(\rho+\beta_{I}\right)+(1-\rho) \beta \gamma m_{s}^{*}\left(\beta, \beta_{I}\right)}{\Pi_{I}\left(m_{s}^{*}(0)\right)-\gamma m_{s}^{*}(0)}-\rho
$$

\section{Proof of proposition 5}

At the equilibrium, the expected payoff of the potential infringer is $G_{I}^{e *}\left(\beta, \beta_{I}, m_{s}^{*}\left(\beta, \beta_{I}\right)\right)$, where $m_{s}^{*}\left(\beta, \beta_{I}\right)$ satisfies equation (13). Firm $I$ is indifferent between entering or not if $G_{I}^{e *}\left(\beta, \beta_{I}, m_{s}^{*}\left(\beta, \beta_{I}\right)\right)=$ 0 . The derivative of $G_{I}^{e *}($.$) with respect to \beta_{I}$ is

$$
\frac{d G_{I}^{e *}}{d \beta_{I}}=\frac{\partial G_{I}^{e *}}{\partial \beta_{I}}+\frac{\partial G_{I}^{e *}}{\partial m_{s}^{*}} \frac{\partial m_{s}^{*}}{\partial \beta_{I}}
$$

Using the envelope theorem, only the direct effect matters and, thus,

$$
\frac{d G_{I}^{e *}}{d \beta_{I}}=-q p_{H}\left(\Pi_{I}\left(m_{s}^{*}\right)-\gamma m_{s}^{*}\right)<0 .
$$

Hence, the expected payoff of the infringer is a decreasing function of $\beta_{I}$. As long as $G_{I}^{e *}\left(0,0, m_{s}^{*}(0,0)\right)>$ 0 , there exists a value of $\beta_{I}$ that we denote $\bar{\beta}_{I}$, for which $G_{I}^{e *}\left(\beta, \beta_{I}, m_{s}^{*}\left(\beta, \beta_{I}\right)\right)=0$. Furthermore, this value is a function of $\beta$. The total differentiation of $G_{I}^{e *}($.$) gives$

$$
d G_{I}^{e *}=\frac{\partial G_{I}^{e *}}{\partial \beta_{I}} d \beta_{I}+\frac{\partial G_{I}^{e *}}{\partial \beta} d \beta=0
$$

and thus,

$$
\frac{d \bar{\beta}_{I}}{d \beta}=-\frac{\frac{\partial G_{I}^{e *}}{\partial \beta}}{\frac{\partial G_{I}^{e *}}{\partial \beta_{I}}}
$$

where $\partial G_{I}^{e *} / \partial \beta_{I}<0$ as defined above and

$$
\frac{\partial G_{I}^{e *}}{\partial \beta}=\frac{\partial G_{I}^{e *}}{\partial \beta}+\frac{\partial G_{I}^{e *}}{\partial m_{s}^{*}} \frac{\partial m_{s}^{*}}{\partial \beta}
$$

Using the envelope theorem,

$$
\frac{\partial G_{I}^{e *}}{\partial \beta}=-\gamma m_{s}^{*} q p_{H}(1-\rho)<0
$$

we can conclude that

$$
\frac{d \bar{\beta}_{I}}{d \beta}<0
$$

Therefore, for a given $\beta_{I}=\beta_{I}^{*}$, there exists a unique $\beta^{*}=\bar{\beta}_{I}^{-1}\left(\beta_{I}^{*}\right)$. 


\section{Proof of corollary 3}

Two cases must be analyzed.

First, if $\beta_{I}^{\prime} \leq \bar{\beta}_{I}(0)$ then the structure of liability levels $B^{\prime}$ defined earlier is optimal. $B^{\prime}$ induces entry, and by construction has a level of license fee identical to $B$.

Second, If $\beta_{I}^{\prime}>\bar{\beta}_{I}(0)$ the structure of damages $B$ fails to induce entry. Let us consider the license fee isoquant (or an iso-license line), $\mathcal{L}($.$) , which is such that the license fee level is L\left(\beta_{I}, \beta\right)$ (or, equivalently, $L\left(\beta_{I}^{\prime}, 0\right)$ ). In the space $\left(\beta_{I}, \beta\right)$, totally differentiating expression (11) shows that the isoquant $\mathcal{L}($.$) is monotonically decreasing with \beta$. Recalling that $\mathcal{L}(\beta)=\beta_{I}<\bar{\beta}_{I}(\beta)$ and $\mathcal{L}(0)=\beta_{I}^{\prime}>\bar{\beta}_{I}(0)$, and that $\mathcal{L}($.$) and \bar{\beta}_{I}($.$) are continuous functions of \beta$, then, given monotonicity, there exists at least one level of indirect liability, say $\widehat{\beta}$, such that $L(\widehat{\beta})=\bar{\beta}_{I}(\widehat{\beta})$. This level induces entry and involves a wider network, since $\widehat{\beta}<\beta$.

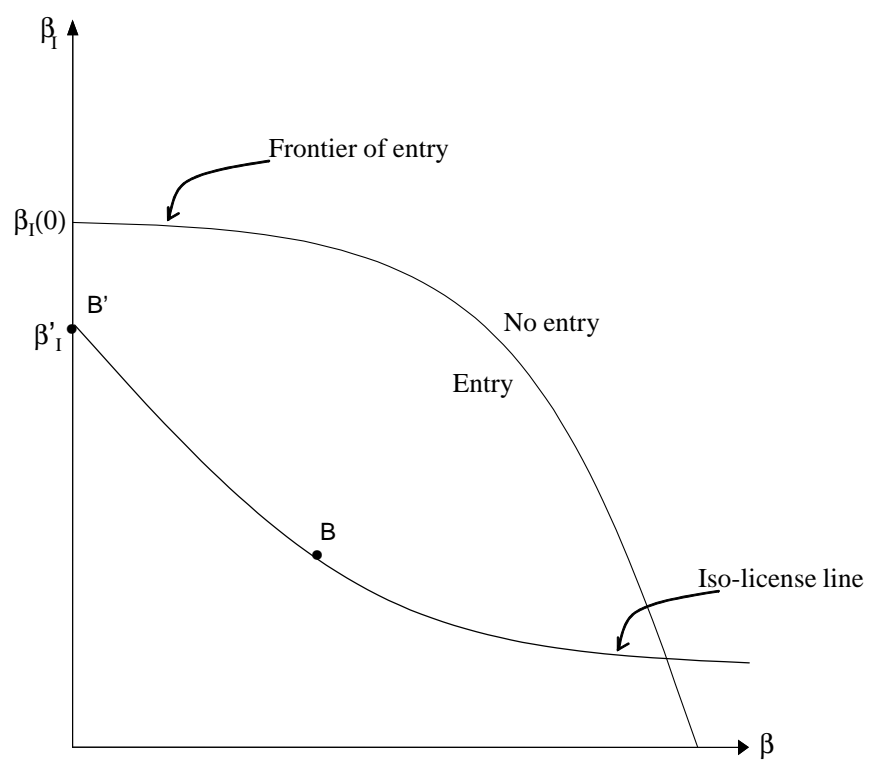

Case if $\beta_{I}^{\prime} \leq \bar{\beta}_{I}(0)$ 